\title{
Reducing the risk of needlestick injuries in hospital
}

\author{
James Denny \\ St George's Hospital
}

\begin{abstract}
After performing procedures involving sharps, many wards in St George's Hospital have no quick and accessible 'point of care' sharps bin for their safe disposal. Instead one must transport potentially hazardous equipment away from the bedside, risking injury and exposure to persons en route.
\end{abstract}

Results from a questionnaire showed that $73 \%$ felt they were indeed poorly placed, $95 \%$ felt a portable sharps bin system was a good idea, and $95 \%$ felt their introduction would be safer. A one month trial of portable sharps bins on the Acute Medical Unit (AMU) showed that $97 \%$ felt that the portable sharps bin system reduced risk to themselves and others, $81 \%$ felt safer using them, and $90 \%$ felt safer knowing their colleagues were using them too.

A recent audit in a six month period within 2012 established there were 148 reported needlestick injuries in St George's Hospital. This quality improvement project showed that a majority consensus felt that a portable sharps bin system would be safer than the system currently used and could potentially help reduce these numbers. This project also comes at a time when new EU legislation calls for safer sharps use and disposal and thus offers a solution to ultimately provide better, safer and more advanced safety practices when disposing of sharp equipment.

\section{Problem}

After performing procedures involving one or multiple sharp pieces of equipment or 'sharps' there is often no quick and accessible sharps bin for their safe disposal. Instead one must transport this equipment, potentially infected with hazardous blood products, away from the bedside to bins situated elsewhere (e.g. end of bays), risking injury and exposure to others en route.

With regards to patient safety, this can be looked at in both the acute and long term settings. Acutely, there is the simple risk of a sharps-related injury plus the potential exposure to hazardous blood products. The long term problem includes the risk of an exposed and seroconverted individual transferring infected blood products to others in the community or workplace as well as the effect it has on the workforce.

There are dozens of scenarios in which the risk of a sharps injury is increased based on the current layout of sharps bin on the ward but some commonly occurring examples are as follows:

1. The further from the bed the sharps bin is, the greater the distance one must walk and the more people and equipment/furniture one may pass to properly dispose of the sharp(s). The more cramped and cluttered the bay is, the more the problem and the subsequent risk are exacerbated.

2. If curtains are pulled around the bed space, one loses focus on the evolving dynamics of the bay with regards to the number of persons in the bay as well as not being able to see who may be walking towards you. When the curtain is pulled open, often with the sharps in the opposite hand, one runs the risk of a potentially harmful collision.

3. Certain times of the day e.g. ward round, visiting hours, drug rounds, nursing handovers, cleaning times etc. all increase the numbers of people and equipment in the already crowded bays thus greatly increasing the risk of an incident.

4. With sharps bins at the end of the bay people take less responsibility for informing the necessary staff as to when they need to be replaced. If you reach a bin post-procedure and it is full then one must travel even further with the sharp(s) to find another

5. Unfolding emergency situations involve multiple personnel in a cramped area with a lot of sharp equipment. "Crash Trolleys" should have sharps bins attached to them but they are usually not removable so physically getting sharps to the bins is hazardous.

It was therefore evident that a solution was needed to a wellestablished problem to help reduce risk and improve quality of sharps disposal in the hospital setting.

\section{Background}

Through passing conversation it became apparent that some colleagues expressed concerns regarding the risk imposed by poorly placed sharps bins. This is non-conducive to effective and safe working practices especially when the use of sharp instruments is undoubtedly a practice performed regularly and throughout all hospitals nationwide. In addition, although some of the current equipment has specially designed sheaths to protect the user these are not available for all equipment and for those that do have them, they are not universally used. Likewise, if a procedure fails, more often than not the sheath protection system fails to activate or is not utilised thus negating its purpose. 
In 2012 the NHS employed 146,075 doctors and 369,868 qualified nursing staff. It also dealt with over one million patients every 36 hours.[1] With such large numbers of staff dealing with sharp equipment and so many patients potentially requiring their use it is unsurprising there are accidental needlestick injuries (NSI's). In fact, a recent statement from the NHS noted that "injuries caused by needles and other sharp instruments are one of the most common and serious risks to healthcare workers. With 40,000 incidents reported each year (and at least as many unreported), this is a major cause for concern for the NHS."[2]

Furthermore, in a National Audit Office report published in 2003, 'A safer place to work - improving the management of health and safety risks in NHS trusts', it was stated that under reporting rates of sharps related injuries may be as high as $85 \%$.[3] The same publication also stated that sharps related injuries accounted for $17 \%$ of accidents to NHS staff nationwide, second only to manual handling accidents (18\%).[3]

When considering the high numbers of people being affected by NSI's it seems illogical to have a disposal system that risks exposure to so many staff, patients, and others which in essence could be made much safer by bringing the sharps bin to the procedure rather than transferring the sharps elsewhere afterwards.

To put the problem in to perspective, and bearing in mind the issue of major under reporting, an audit of sharps, splash, and bite injuries between July to December 2010 established that there were 120 injuries to St George's Hospital (SGH) staff reported, of which 85 were NSI's. [4] The provisional cost of those 120 injuries was $£ 53,000$, which covered necessary staff, lab work, and medication but excluded lost man hours related to stress and side effects of any ensuing medication.[4] Further to this, another audit between January and June 2012 found even more, with 148 NSI's reported in SGH across a similar time frame.[5]

Most of the injuries occur on the wards, in A\&E, and Theatres. Of these, source testing revealed seven positive results; five were infected with Hepatitis C Virus (HCV) and two with Human Immunodeficiency Virus (HIV). Although only a fraction were known to be infected with high risk blood borne viruses (BBV), the numbers are still significant.

The pathogens that contribute the greatest concern are most certainly Hepatitis B Virus (HBV), HCV and HIV but there are many others that can be transmitted including other strains of Hepatitis, Epstein Barr Virus (EBV), parvovirus B19 and possibly prions (thought to be linked to transmissible spongiform encephalopathies).[6] HBV, HCV and HIV remain difficult to contract via NSI's but people do seroconvert and people do die from them.[3] It has been shown that when exposed to a percutaneous injury with a sharp instrument infected with HBV, HCV or HIV the transmission rate is approximately $30 \%, 3 \%$ and $0.3 \%$ respectively.[7] In addition, the psychological effect of an NSI, even if no pathogen is identified can be significant and reticence of an affected individual to use sharp equipment can be prolonged.

From 11th May 2013 the NHS became bound by a new EU
Directive for the Prevention from Sharp Injuries in the Hospital and Healthcare sector. The aim of this directive, amongst other things, is to further reduce risk and increase safety and protection of its workers. [8] This project helps identify problems in the workplace which this directive aims to improve upon and will hopefully supplement the work already done by SGH to ultimately improve health and safety in the workplace. In addition to this new directive it is worth mentioning that there are additional pieces of health and safety legislation related to sharps injuries that hospitals already have to abide by. This includes The Health and Safety at Work etc. Act (1974) [9] and The Health Act (2006) [10] plus four others [11-14] and three EU directives. [15,16,17]. The legal obligations can also be extended to include those surrounding the provision of sharps disposal systems whereby The Care Quality Commission (CQC) provides necessary licenses to NHS healthcare services if they meet the standards dictated by the aforementioned acts.

With a significant amount of legislation surrounding this topic, implementing change undoubtedly imparts additional financial duties to NHS healthcare organisations. However, it is worth noting that in 2004 a legal ruling against the Scottish Ambulance Service stated that cost cannot be a reason not to provide safety equipment for sharps, as it breached the aforementioned European health and safety laws.[18] The NHS therefore has its own extensive policies surrounding the health and safety issues for NSI's and SGH being an NHS facility should follow them. The NHS Employers document, 'Needlestick Injury' produced in 2011 explicitly states a number of key guidance points which are adapted from the World Health Organisations (WHO) guidance "hierarchy of control".[6] There is a large amount of guidance but some of the points, specifically related to sharps disposal suggest the following:

1. Where possible, there should be access to "adequate numbers of easily accessible sharps disposal containers"[6]

2. Reducing exposure to occupational hazards can be achieved by "placing sharps containers at eye level and within arm's reach"[6] and"disposing of sharps immediately after use in designated sharps containers"[6]

3. All sharps should be disposed of carefully at the point of use. This means that suitable sharps containers (conforming to British Standard BS EN ISO 23907:2012) [19] should be portable enough to take to the site of a procedure, and designed specifically to allow needles and sharp instruments to be disposed of easily and safely at the point of use.

From all of the above legislation, policy and guidance is would appear that a portable sharps system was a likely candidate to help meet these health and safety expectations and so was chosen to go forward to trial to see if it had a place in $\mathrm{SGH}$.

\section{Baseline Measurement}

Initially it had been a number of staff, mainly doctors who advocated for their wards, who verified there was an issue with the layout of sharps bins in their workplace. A questionnaire was therefore circulated amongst many staff members of differing roles and disciplines across the hospital to formally assess if this was not just 


\section{BMJ Quality Improvement Reports}

a select group of worried individuals. The questionnaire firstly divulged the whereabouts of the person's workplace and their role. It then contained several questions that allowed the partaker to personally identify any concerns over safety or risk and if our solution could potentially benefit them and those around them in their workplace. A total of 37 questionnaires were returned and data implied:

$73 \%$ felt sharps bins are poorly placed. Of this population, $63 \%$ felt that they themselves were at risk with the current sharps bin system and $70 \%$ felt others were at risk too. $100 \%$ of this population felt portable sharps bins were a good idea and $96 \%$ said they would feel safer with them.

Of the $27 \%$ that did not feel sharps bins were poorly placed, $50 \%$ still felt that they themselves were at risk with their current sharps bin set-up; likewise $50 \%$ felt others were at risk too. Furthermore, of this $27 \%$ population, $80 \%$ felt portable sharps bins were a good idea, and $80 \%$ said they would feel safer with them. It is important to note, that the remaining $20 \%$ consisted purely of General Intensive Care Unit staff where every patient has their own sharps bin by the bedside.

Of the overall sample population, $95 \%$ felt portable sharps bins were a good idea and $95 \%$ said they would feel safer with their introduction.

The result of these questionnaires identified the vast majority felt unnecessarily exposed and that the simple implementation of portable sharps bins could ease the risk to them, their colleagues, and other persons on the ward. A copy of the questionnaire is attached. In addition, it is worth noting that although most wards in the hospital do not have portable sharps bins, some such as Heberden, McEntee, and Dalby ward do. The difference in practice regarding handling of sharps and safety of personnel within the same hospital seems illogical and further suggests the need for a standardised policy regarding the use of sharps bins.

See supplementary file: ds1246.doc - "Staff Questionnaire regarding reducing the risk of sharps"

\section{Design}

We proposed the trial of portable sharps bins allowing for the immediate disposal of sharps at the point of care thus reducing the risk of unnecessary exposure. Since portable sharps bins systems are already in use on certain wards then it is apparent they are sustainable there. In fact portable sharps bins systems are already used within many hospitals nationwide so in affect their sustainability is already proven. The exact reason portable bins are not used on all wards is not known to current ward staff but it is not secondary to cost nor should it be when considering the legal opinion around finance and sharps disposal.

We chose to base the trial on the Acute Medical Unit (AMU). We chose AMU because we wanted a ward with:
2. Large numbers of staff

3. High numbers of procedures where NSI's are a regular risk

4. Multi-disciplinary teams

The device we chose to trial was a 2.5 litre round sharps bin with attachable (and reusable) tray. This bin was selected from the suppliers catalogue as it was deemed neither too big to be heavy and cumbersome, nor too small so as to limit the range of equipment that could be disposed of in them.

It is important to note that that the use of portable sharps bins is not a universal solution. They are part of a holistic approach to safer disposal of sharps and should be used in conjunction with already established measures.[20] These include continuous education and training, not re-sheathing needles, and the use of gloves (which has been shown to remove $86 \%$ of blood from the outside of a needle when punctured).[21]

\section{Strategy}

The primary PDSA Cycle provided highly positive results in favour of portable sharps bins and did not necessitate the need for further cycles.

See supplementary file: ds1606.doc - "PDSA Cycle 1"

\section{Post-Measurement}

After the trial a questionnaire was circulated to assess the response from staff members that used them. The questionnaires were completed by a variety of doctors, nurses, and health care assistants, all of varying grades. 31 questionnaires were returned and data implied:

$97 \%$ felt that the portable sharps bin system reduced risk to themselves and others

$81 \%$ felt safer using the portable sharps bin system

$90 \%$ felt safer knowing their colleagues were using the portable sharps bin system

$87 \%$ felt the portable sharps bin system were user friendly

$90 \%$ would be happy for the portable sharps bin system to be continuously implemented on AMU

The $13 \%$ that felt they were not user friendly said:

- They took up too much room on the trolleys in the bays (two persons)

- If you fall over carrying the portable sharps bin you risk spilling its contents (one person)

- One person did not see the point of them (one person)

1. High turnover 


\section{BMJ Quality Improvement Reports}

$45 \%$ felt that the portable sharps bin system could be improved and these were their suggestions:

- They could be smaller (four persons)

- Staff need education on their use so as not to accidentally dispose of the reusable tray (two persons)

- They allowed for a situation where staff were not cleaning the trays properly (two persons)

- AMU needed more of them (four persons)

- They should be rolled out hospital wide (one person)

*n.b. one person left two comments.

We see the four remarks for AMU needing more portable sharps bin systems and the one for rolling them out hospital wide as positive remarks since this was only a trial on a single ward. If we exclude these five positive remarks then the new percentage for those who felt that the portable sharps bin system needing improving is only $31 \%$.

Of those that felt they did not need improving, the following positive feedback was obtained:

- They were a good size (two persons)

- They were easy to use (three persons)

- They were safe for staff and patients (five persons)

- They were useful (one person)

There was some mild resistance to a possible change in the use of equipment however the majority of questionnaires showed that people welcomed the idea of portable sharps bins. The overall data therefore implied that portable sharps bins would be accepted if they were introduced into the clinical environment.

See supplementary file: ds1607.docx - "Trial Run of Sharps Bin Data"

\section{Lessons and Limitations}

Problems encountered \& what was learned:

1. Getting people to complete and return questionnaires within working hours was extremely difficult. Only a small percentage of those handed out were returned and we thank the staff who went out of their way to get more forms filled in only because they supported the cause.

2. Getting the initial trial under way took a long time as we had to hand the ordering of equipment over to other staff who firstly did not understand the time frame we were working to plus decided to order what they felt was best rather than what we had asked. I learned that it was key to limit the number of people involved in the transferal of information and requests.

3. People do not like change. We were met with hostility from some staff who did not like that we were trying to change their work practice. Fortunately, we were met with much more support than hostility but it was still difficult to deal with, especially when ultimately we were trying to improve safety. We have to constantly remember the bigger picture and not let individual negativity prevent progress.

\section{Conclusion}

The aim of this project was to identify if informal feelings about the risk imposed to staff, patients, and other members of the public regarding the sharps bin system in St George's Hospital was real and if a portable sharps bin system could help. Initial data showed an overwhelming agreement that people did feel that a portable sharps bin system would be safer than the current system and that it would be beneficial to all. It also revealed a disparity across the hospital since some wards already used them. With this information and knowledge of current and encroaching legislation regarding safer sharps disposal practices we gained the support of the team involved in such matters for St George's Hospital. The project then progressed to a trial run of a portable sharps bin system in the Acute Medical Unit which showed that the vast majority of staff felt that their introduction on the ward was a positive and necessary safety measure. The results of this project suggest the need for hospital-wide usage of a portable sharps bin system to maintain better, safer, and more advanced safety practices when disposing of sharp equipment. Additionally, it will hopefully suggest the same to other healthcare institutes in the UK.

\section{References}

1. NHS Confederation. Key Statistics on the NHS [online] 2012. [Accessed 22nd May 2013] Available from: http://www.nhsconfed.org/priorities/politicalengagement/Pages/NHS-statistics.aspx [press release]

2. NHS. Prevention of sharps injuries [online]. 2012. [Accessed 22nd May 2013]. Available from:

http://www.nhsemployers.org/employmentpolicyandpractice/ european_employment_policy/pages/initiatives-onneedlestick-injuries.aspx [press release]

3. The National Audit Office. The National Audit Office (NAO) report, A safer place to work - improving the management of health and safety risks in NHS trusts, 2003

4. St George's Healthcare NHS Trust Occupational Health Department. Audit of Sharp, Splash and Bite Injuries (1st July 2010 to 31st December 2010), 2011

5. St George's Healthcare NHS Trust Occupational Health Department. Audit of needle stick injuries over 6 months in St George's Hospital (Jan to June 2012), 2012

6. NHS EMPLOYERS. Needlestick Injury. NHS Employers [online], 2011 [Accessed 22nd May 2013]. Available from: http://www.nhsemployers.org/SiteCollectionDocuments/Nee dlestick Injury (22 02 2011).doc

7. Elmiyeh B, Whitaker IS, James MJ, Chahal CAA, Galea A, 


\section{BMJ Quality Improvement Reports}

Alshafi K. Needle-stick injuries in the National Health Service: a culture of silence. Journal of the Royal Society of Medicine. 2004 Jul;97(7):326-327

8. EUROPEAN COUNCIL Directive 2010/32/EU of 10th May 2010 on the prevention of sharps injuries in the hospital and the healthcare sector.

9. Great Britain. The Health and Safety at Work etc. Act 1974: London: The Stationery Office

10. Great Britain. The Health Act 2006: London: The Stationery Office

11. Great Britain. The control of substances hazardous to health regulations 2002: London: The Stationery Office

12. Great Britain. The Management of Health and Safety at Work Regulations 1999: London: The Stationery Office

13. Great Britain. The Reporting of Injuries, Diseases and Dangerous Occurrences Regulations (RIDDOR) 1995: London: The Stationery Office

14. Great Britain. The Safety Representatives and Safety Committee Regulations 1977: London: The Stationery Office

15. EUROPEAN COUNCIL Directive 89/391/EEC of 12 June 1989 on the introduction of measures to encourage improvements in the safety and health of workers at work

16. EUROPEAN COUNCIL Directive 89/655/EEC of 30 November 1989 concerning the minimum safety and health requirements for the use of work equipment by workers at work

17. EUROPEAN COUNCIL Directive 2000/54/EC of the European Parliament and of the Council of 18 September 2000 on the protection of workers from risks related to exposure to biological agents at work

18. IAIN HENRY SKINNER vs. SCOTTISH AMBULANCE SERVICE A324/03

19. BRITISH STANDARDS INSTITUTION (2012) BS EN ISO 23907: Sharps injury protection. Requirements and test methods. Sharps containers. London, British Standards Institution.

20. Zanni GR, Wick JY. Preventing needlestick injuries. Consultant Pharmacist. 2007 May;22(5):400-2, 404-6, 409

21. Mast ST, Woolwine, JD, Geberding JL. Efficacy of gloves in reducing blood volumes transferred during simulated needlestick injury. Journal of Infectious Diseases. 1993;168(6):1589-92

\section{Declaration of interests}

Nothing to declare 